\title{
Thoracic surgery in Australia
}

\author{
Gavin Michael Wright ${ }^{1,2,3,4} \wedge$ \\ ${ }^{1}$ Director of Surgical Oncology, St. Vincent's Hospital, Melbourne, Australia; ${ }^{2}$ Department of Surgery, University of Melbourne, St Vincent's \\ Hospital, Melbourne, Australia; ${ }^{3}$ Research and Education Lead for Lung Cancer, Victorian Comprehensive Cancer Centre, Melbourne, Australia; \\ ${ }^{4}$ Division of Cancer Surgery, Peter MacCallum Cancer Centre, Melbourne, Australia \\ Correspondence to: Gavin Michael Wright. 5th Floor, 55 Victoria Parade, Fitzroy, VIC 3065, Australia. Email: Gavin.Wright@svha.org.au.
}

Submitted Jul 06, 2021. Accepted for publication Oct 18, 2021.

doi: $10.21037 /$ jtd-21-1623

View this article at: https://dx.doi.org/10.21037/jtd-21-1623

\section{Introduction}

Thoracic (non-cardiac) surgery in Australia is a relatively small sub-specialty of cardiothoracic surgery. It is for the most part, a surgical oncology specialty. This paper, part of the Thoracic Surgery Worldwide series, details the breadth and depth of thoracic surgery practice, research, and training in the context of its geographic, political, and demographic background.

\section{Demographic and health service environment}

Australia is a federation of six sovereign states and several territories (including the autonomously governed Northern Territory and Australian Capital Territory). It had a population of 25.5 million as of 2020. The most populous states are New South Wales (NSW) and Victoria, with populations of 8.2 and 6.7 million, respectively. Most Australians live in coastal capital cities such as Sydney, Melbourne, and Brisbane in the east, with smaller cities of Adelaide and Perth towards the South and far West of the continent.

Parts of Australia are truly remote, with small populations, and thousands of kilometres from major centres. Tasmania and Northern Territory rely on the neighbouring states of Victoria and South Australia, respectively, for many specialised medical interventions, as their populations are too small to be sustainable services.

The national health system consists of two overlapping layers of insurance. Universal health cover (Medicare - funded by the Federal Government) provides free hospital care in the State-based health jurisdictions and provides a rebate for private primary care and specialist consultations and some interventions. Optional private hospital insurance allows choice of specialist and admission to private hospitals, where services are far less rationed due to fee-forservice arrangements. The patient retains the right to claim the Medicare rebate for private hospital episodes of care, with the balance made up from private insurance, with or without additional patient contributions. To claim rebates, a patient must have been referred to a surgeon by a general practitioner (primary care physician) or another specialist.

Both the public and private health systems are highly sophisticated, with good access to high technology interventions such as PET scanning, MRI scanning, stereotactic radiotherapy, robotic surgery and EBUS. The Pharmaceutical Benefits Scheme provides equitable lowcost supply of even the most expensive drugs if they have been approved through an evidence-based process. This includes access to immunotherapy agents and tyrosine kinase inhibitors for their approved indications.

Data collection is a glaring deficiency in Australia, with only two states having any consolidated population-based data for thoracic surgery, with neither having complete capture. The Australian Institute of Health and Welfare do collect total numbers of cases and deaths from all cancers, as do the state-based Cancer Councils. However, surgical data of any granularity is lacking. Estimates in this paper therefore rely heavily on generalising these data sources to the national population.

$\wedge$ ORCID: 0000-0002-7000-9305. 


\section{Lung cancer in Australia}

Like most countries, lung cancer is the signature disease of the specialist thoracic surgeon. At more than 13,000 cases per year, it is the most common cause of cancer death in Australia and is the fourth most common cancer by incidence. It disproportionately affects Indigenous Peoples, lower socioeconomic groups and the incarcerated population. Indigenous Australians are twice as likely to develop lung cancer, and then twice as likely to die from that disease than non-indigenous Australians (1). It is the highest incidence cancer in this group.

Smoking prevalence is low in Australia compared to most European and Asian countries. It has similar rates to California, with $11.6 \%$ estimated from the National Drug Household Survey in 2019 (2). However smoking rates amongst Indigenous Peoples remain high at $43.4 \%$.

As there is no lung cancer screening program in Australia, lung cancer mostly presents as late-stage disease. Five-year survival rates have doubled over the last two decades but remain at 19\% (2). A recent government-commissioned Lung Cancer Screening Enquiry strongly recommended a program be developed (3) and the Federal Government has since set aside funds to scope its implementation.

Multi-disciplinary team (MDT) approaches to most cancers are commonplace in Australia. These are usually based in the public hospital system, but open to attendance by all specialists treating patients in the relevant tumour stream. Lung cancer MDTs are very well established, although in regional areas and smaller cities, they are deficient in thoracic surgery input, or rely on telemedicine links.

Of the 1,772 diagnosed with NSCLC in Victoria in 2018, $58.9 \%$ had Adenocarcinoma, $22.7 \%$ had Squamous Cell Carcinoma, $1.2 \%$ had Large Cell Carcinoma and 17.2\% were not otherwise specified (NOS) (4).

For clinical stages I and II, 65\% of NSCLC cases are treated by surgical resection (4), The overall resection rate averages about $20 \%$ across Australia, resulting in an estimated 2,600 lung resections in 2020.

\section{Thoracic surgery training}

The pathway to becoming a thoracic surgeon in Australia begins with pre-clinical (university-based) and clinical (hospital-based) medical school training. These were originally dedicated 5- or 6-year courses, but now almost exclusively follow a pre-medical science degree, with
3-4 years of dedicated medical school. A research year is usually proscribed. An internship of one year is then required by law to be registered as a medical practitioner. This consists of minimum terms in medical, surgical, and emergency wards.

The Royal Australasian College of Surgeons is a binational (Australia and New Zealand) organisation that has specialty boards responsible for the administration of accredited surgical training in Australia since its foundation in 1927. For all surgical specialties, a Fellowship of the Royal Australasian College of Surgeons (FRACS) consists of an entry examination and experience criteria, interim assessments and supervisor reports, and an exit examination. Nearly all accredited training is delivered in the public hospital systems of Australia and New Zealand. Training posts are re-accredited on a 5-year cycle, or more regularly if a problem has been identified or reported to the Board of Cardiothoracic Surgery.

The Board of Cardiothoracic Surgery program is currently six years in duration and very heavily weighted towards cardiac surgery. As there are relatively few dedicated thoracic surgical units in Australia, there are only 2-3 accredited thoracic surgical training positions each year. The FRACS in Cardiothoracic Surgery can be awarded even if no training has been performed in a specialist thoracic surgical unit. "Thoracic-interested" trainees will spend 12 months, at most, in such a unit in their six years of accredited training. This is a known weakness in the Australian system is partially responsible for the small workforce of specialist thoracic surgeons.

\section{Thoracic surgery workforce}

A Fellowship of the Royal Australasian College of Surgeons is required to identify as a cardiothoracic surgeon for hospital accreditation and to attract specialist rebates from Medicare for patients. In practice, thoracic surgery is performed by cardiothoracic surgeons, pure thoracic surgeons and selected general surgeons with additional thoracic training. There is a representative specialty body affiliated with the College, the Australian and New Zealand Society of Cardiac and Thoracic Surgeons (ANZSCTS), but membership is not required to maintain clinical practice. For this reason, it is difficult to quantify the precise number of surgeons with significant regular thoracic practice in Australia. It is estimated by the ANZSCTS that there are close to 150 cardiothoracic surgeons in Australia. Pure or majority thoracic surgeons make up $10 \%$ of this number. 
There is a lack of diversity in this small group, all being male. and ethnically of South or East Asian, or European descent. There are no Australian Indigenous specialist thoracic surgeons.

Although thoracic surgeons individually have the highest per capita caseload of lung cancer surgery, the low numbers of pure thoracic surgeons ( $<1$ per million population) means most lung cancer resections in Australia are performed by cardiothoracic surgeons (6 per million population), and a small number are performed by general surgeons in regional cities.

Typically, a specialist thoracic surgeon would resect 40 100 lung cancers per year, with the remainder of surgical time performing diagnostic or palliative procedures, nonmalignant surgery, or surgery for other thoracic primary malignancies. The thoracic workload of cardiothoracic surgeons is highly variable, ranging from 0-40 lung cancer resections per year.

Over the last 10-20 years, there has been steadily reduced involvement of cardiothoracic and thoracic surgeons in the management of esophageal cancers. In Australia, these are usually distal or junctional adenocarcinomas and are treated by general surgeons with upper gastrointestinal sub-specialisation. The rarer mid-thoracic esophageal cancers are more commonly co-managed by general and cardiothoracic surgeons. There are therefore minimal training opportunities for thoracic surgeons today, unless they first complete a General Surgery program prior to entering Cardiothoracic Surgery training.

Paediatric thoracic surgery in Australia is performed almost exclusively by paediatric (general) surgeons up until the age of 16.

Lung transplantation is a separate specialty within cardiothoracic surgery and only takes place in one designated hospital for each of the largest states. It is not part of the routine practice of specialist thoracic surgeons.

\section{Thoracic surgical practice}

Minimally invasive surgical techniques have taken a very long time to establish a foothold in Australia since its first VATS lobectomy was performed in 2000. Until the last decade, only a few dedicated centres, mostly located in Melbourne, were performing VATS procedures with higher complexity than wedge resections or pleural procedures. Since 2015 , there has been a steady rise in uptake. According to the Queensland Cardiac Outcomes Registry, the only published population-based source dedicated to thoracic surgery data, $62 \%$ of thoracic surgery was performed by VATS in 2018 (5) and 49\% in 2019 (6). The rates are higher in NSW and Victoria, with the author's own thoracic unit exceeding $90 \%$ of lobectomies by VATS over the last decade, with a conversion rate of $2.5 \%$.

Robotic surgery access and utilisation varies greatly across Australia. There is currently only access available to surgeons in the Eastern mainland States of Victoria, NSW, and, most recently, Queensland. A total of 443 thoracic surgery cases were registered on da Vinci robot installations in Australia in the last 12 months (Source: Device Technologies Australia).

In NSW (population: 8.2 million), 260 thoracic robotic cases were performed in the last year, across 7 private and 4 public hospitals.

In Victoria (population: 6.7 million) 174 thoracic robotic cases were performed in the same timeframe, across 7 private and 3 public hospitals. One additional public hospital shares the use of a co-located private hospital robot.

In Queensland (population: 5.2 million), there have only been 9 thoracic cases in 2 private and 1 public hospital in that time.

Most robotic surgery is less complex, such as removal of thymomas or neurilemmomas, thymectomy for myasthenia and wedge resections. Anatomic lung resections such as lobectomy and segmentectomy require additional credentialling and proctorship in most hospitals with robotic facilities. International proctors from France and USA have been used to credential surgeons in Victoria and NSW to act as local proctors for complex segmentectomy and lobectomy.

Uniportal VATS (UVATS) does not have a large uptake in Australia, despite the country having been twice toured by Dr. Diego Gonzalez Rivas. However, inspired by his initial visit at the end of 2017, a UVATS training program was developed in Melbourne (7). The author is the main proponent in Melbourne, performing 200 complex major cases by UVATS, compared to 170 complex major cases by robotic surgery in a similar time frame.

Like elsewhere in the developed world, mediastinoscopy is fading as an investigative procedure as EBUS has established itself as the dominant investigative tool for lymphadenopathy. It is still used for failed EBUS, wherever EBUS is not available, and for better sub-typing of lymphoma. Only a small number $(<10)$ of thoracic surgeons have incorporated EBUS into their skillset. Respiratory physicians with bronchology practice perform the vast 
majority of EBUS in Australia, partly because of training opportunities and partly because of the relative scarcity of specialist thoracic surgeons.

Salvage or planned surgery after radical radiotherapy is offered at a few thoracic surgery units. Stage IIIB lung cancer is treated non-surgically in Australia (8).

Across Australia, sternotomy is the still most common access for thymic surgery, however VATS and robotic techniques are exclusively used in specialized centres in Melbourne and Sydney to treat small thymomas and myasthenia gravis.

Tracheal surgery is concentrated to hospitals with a specific interest, and is divided between thoracic surgeons, in some states, and head and neck surgeons in others.

\section{Lung cancer quality indicators}

There is no legislative restriction on where a lung cancer resection can take place. However, in practice, most are done in the state capital cities and large secondary centres. Outside of the state of Queensland, there is still no specific mandatory audit of lung cancer surgery or thoracic surgery, despite 20 years of mandatory national cardiac surgery audits with public reporting.

In Victoria, nine of the nineteen hospitals reporting lung cancer resection perform $\geq 30$ resections per annum and about a third of hospitals perform $<15$ resections per annum. Three hospitals performed only a single lung cancer resection (4). These low volume sites raise the concern that optimal cancer care may not be delivered to all. By contrast, in Queensland, with a much more centralised health system and only five public hospitals performing lung cancer surgery, four hospitals performed $\geq 30$ resections per annum, with the fifth hospital performing 20 (6).

According to the Victorian Lung Cancer Registry, which covers a population of 6.5 million, $82 \%$ of patients with lung cancer were registered to a multidisciplinary team meeting (tumor board) (4). In the equivalent data for the state of Queensland, 58\% had documented discussion in a multidisciplinary team meeting (9).

Of the 1,772 patients in the Victorian registry in 2018, $476(27 \%)$ underwent surgery. The rates of surgery for stage 1 and 2 were $71 \%$ and $53 \%$, respectively. Less than $2 \%$ of patients actively declined surgery when offered. PET scans were performed pre-operatively in $91 \%$ of cases (4). Audits of surgery in general confirm that thoracic surgery is practiced safely in Australia in terms of acceptable mortality, but the quality of oncologic surgery is less clear.
A data linkage study from NSW, estimated that 38-43\% of 'localised' NSCLC cases were treated with resection. Localised was defined as "confined to the lung". The study reported that $30 \%$ of presentations were localised, giving a resection rate of less than $15 \%$. However, socioeconomic disparities clearly influenced resection rates, with more affluent local government areas having 59\% of localised NSCLC resected (10). The study concluded that resection rates across much of the state were below optimal levels.

\section{Continuing medical education}

Continuing medical education is a mandatory requirement to maintain Fellowship of the Royal Australasian College of Surgeons. Minimum requirements are set in a range of areas including audit, reflective practice, clinical governance \& quality improvement, and maintenance of knowledge and skills. Surgeons are allowed a 3-year cycle in which to meet or exceed the annual requirements.

\section{Research}

Research in lung cancer for surgeons is limited in Australia due to few opportunities, lack of funding and the small size of the specialty. There has been general participation in clinical trials of adjuvant or neoadjuvant therapies. St Vincent's Hospital in Melbourne contributed to the US National Cancer Institute-sponsored ACOSOG Z30 (11) and CALGB 140503 (12) trials and published a Cochrane review and meta-analysis of surgery for NSCLC (13).

The Baird Institute for Applied Heart and Lung Surgical Research in Sydney has published multiple systematic reviews of minimally invasive surgical techniques $(14,15)$. More recently, there has been an upswing in multi-centre clinical trial and translational research across thoracic surgical units in Melbourne, facilitated by the new Victorian Comprehensive Cancer Centre (VCCC). The VCCC is currently the world's third highest recruiter of patients for the StableMates trial (16) (SABR versus sublobar resection of stage 1 NSCLC in patients at higher risk for lobectomy).

\section{The future}

The major deficiency of a national comprehensive thoracic surgery data source is being addressed currently by the Australian and New Zealand Society of Cardiac and Thoracic Surgeons. At the time of this report, a working party has almost completed the creation of ANZTHOR, 
a quality registry database. The main purpose of the database will be to report back adherence to key NSCLC surgical quality indicators to surgeons, heads of thoracic and cardiothoracic surgical units and hospitals. It will also publish benchmarks such as rates of benign resections for suspected lung cancer, 30- and 90-day mortality.

One emerging area for thoracic surgery is fluorescenceguided surgery, particularly for the increasing use of segmentectomy for early NSCLC and oligo-metastatic disease from extra-pulmonary cancers, and for marking small tumours pre-operatively.

Future challenges for thoracic surgery in Australia remain the imbalance of specialist thoracic surgical training within the cardiothoracic training program and the translation of clinical trial findings into routine practice. The place of new technology, such as robotic surgery or even complex uniportal VATS, is uncertain due to limited availability in public hospital settings, the predominant source of training for future thoracic surgeons.

\section{Acknowledgments}

The author wishes to acknowledge the assistance of Dr. Chris Cole in sourcing registry data for thoracic surgery and lung cancer management in Queensland.

Funding: None.

\section{Footnote}

Provenance and Peer Review: This article was commissioned by the Guest Editor (Alan D. L. Sihoe) for the series "Thoracic Surgery Worldwide" published in fournal of Thoracic Disease. The article has undergone external peer review.

Conflicts of Interest: The author has completed the ICMJE uniform disclosure form (available at https://jtd.amegroups. com/article/view/10.21037/jtd-21-1623/coif). The series "Thoracic Surgery Worldwide" was commissioned by the editorial office without any funding or sponsorship. The author has no other conflicts of interest to declare.

Ethical Statement: The author is accountable for all aspects of the work in ensuring that questions related to the accuracy or integrity of any part of the work are appropriately investigated and resolved.

Open Access Statement: This is an Open Access article distributed in accordance with the Creative Commons Attribution-NonCommercial-NoDerivs 4.0 International License (CC BY-NC-ND 4.0), which permits the noncommercial replication and distribution of the article with the strict proviso that no changes or edits are made and the original work is properly cited (including links to both the formal publication through the relevant DOI and the license). See: https://creativecommons.org/licenses/by-nc-nd/4.0/.

\section{References}

1. Australian Government. National Mortality Database 2019. Australian Institute of Health and Welfare, Canberra, 2020. Available online: https://www.aihw.gov.au/ about-our-data/our-data-collections/national-mortalitydatabase

2. Australian Government. Cancer Data in Australia. Australian Institute of Health and Welfare, Canberra, 2021. Available online: https://www.aihw.gov.au/reports/ cancer/cancer-data-in-australia/contents/summary

3. Cancer Australia, 2020. Report on the Lung Cancer Screening Enquiry, Cancer Australia, Surry Hills, NSW.

4. Stirling R, Martin C, Brand M, et al. The Victorian Lung Cancer Registry Annual Report, 2018. Monash University, Department of Epidemiology and Preventive Medicine, Report No 5.

5. Queensland Government. Queensland Cardiac Outcomes Registry. Cardiothoracic Surgery Audit 2018. Queensland Health, Brisbane, 2019.

6. Queensland Government. Queensland Cardiac Outcomes Registry. Cardiothoracic Surgery Audit 2019. Queensland Health, Brisbane, 2020.

7. Shukla R, Vijayapuri S, Rahnavardi M, et al. Initial experience in uniportal video-assisted thoracoscopic surgery (VATS) for major lung resections-Australia's first uniportal VATS teaching program. J Vis Surg 2019;5:42.

8. John T, Cooper WA, Wright G, et al. Lung Cancer in Australia. J Thorac Oncol 2020;15:1809-14.

9. Queensland Government. Queensland Cancer Quality Index: Indicators of safe, quality cancer care. Cancer care in public and private Hospitals 2003-2017. Queensland Health, Brisbane, 2020.

10. Currow DC, You H, Aranda S, et al. What factors are predictive of surgical resection and survival from localised non-small cell lung cancer? Med J Aust 2014;201:475-80.

11. Darling GE, Allen MS, Decker PA, et al. Randomized trial of mediastinal lymph node sampling versus complete lymphadenectomy during pulmonary resection in the 
patient with $\mathrm{N} 0$ or N1 (less than hilar) non-small cell carcinoma: results of the American College of Surgery Oncology Group Z0030 Trial. J Thorac Cardiovasc Surg 2011;141:662-70.

12. Altorki NK, Wang X, Wigle D, et al. Perioperative mortality and morbidity after sublobar versus lobar resection for early-stage non-small-cell lung cancer: post-hoc analysis of an international, randomised, phase 3 trial (CALGB/Alliance 140503). Lancet Respir Med 2018;6:915-24.

13. Campbell DA. Surgery for non-small cell lung cancer: systematic review and meta-analysis of randomised

Cite this article as: Wright GM. Thoracic surgery in Australia. J Thorac Dis 2022;14(2):579-584. doi: 10.21037/jtd-21-1623 controlled trials. Thorax 2006;61:597-603.

14. Cao C, Manganas C, Ang SC, et al. A meta-analysis of unmatched and matched patients comparing videoassisted thoracoscopic lobectomy and conventional open lobectomy. Ann Cardiothorac Surg 2012;1:16-23.

15. Cao C, Manganas C, Ang SC, et al. A systematic review and meta-analysis on pulmonary resections by robotic video-assisted thoracic surgery. Ann Cardiothorac Surg 2012;1:3-10.

16. US National Library of Medicine 2021, accessed 10 October 2021. Available online: https://www.clinicaltrials. gov/ct2/show/NCT02468024 